\title{
Effect of cereal fibre source and processing on rectal epithelial cell proliferation
}

\author{
F A Macrae, D Kilias, L Selbie, M Abbott, K Sharpe, G P Young
}

Department of Gastroenterology, Royal Melbourne Hospital, Parkville, Victoria, Australia F A Macrae

L Selbie

M Abbott

Department of Medicine, University of Melbourne, Parkville, Victoria, Australia D Kilias

F A Macrae

Department of Statistics, University of Melbourne, Parkville, Victoria, Australia K Sharpe

University of Adelaide, Department of Medicine, The Queen Elizabeth Hospital, South Australia G P Young

Correspondence to: Dr F A Macrae Department of Gastroenterology, The Royal Melbourne Hospital,

Parkville, Victoria, Australia.

Accepted for publication 20 February 1997

\begin{abstract}
Background-Low fat and wheat bran interventions significantly reduced the growth of small to large adenomas and modestly suppressed rectal epithelial cell proliferation in the Australian Polyp Prevention Project.

Aim-To study the effect of unprocessed wheat bran, unprocessed oat bran and processed wheat bran (Kellogg's All Bran) on rectal epithelial cell proliferation.

Patients-Twenty subjects with recent adenomas and a high fat background diet were recruited.

Methods-Rectal biopsy specimens were taken at entry and at the end of three sixweek periods of oat bran (64 g/day), wheat bran ( 25 g/day) and All Bran (38 g/day), all in association with a diet $<25 \%$ energy as fat, in a randomised cross-over trial. Each of the bran supplements had a total of $11 \mathrm{~g}$ dietary fibre. The biopsy specimens were fixed in methacarn and stained immunohistochemically for presence of the proliferating cell nuclear antigen (PCNA). The kinetics used to measure proliferation were labelling index, whole distribution of labelled cells, and labelled cells in the top two-fifths of crypts using analysis of variance.
\end{abstract}

Results-There were no significant differences in mean labelling indexes between the four diets or in the percentage of labelled cells in the top two-fifths $(p=0.59)$, but activity in the top two-fifths of crypts was lowest with wheat bran. The mean (SD) labelling indexes were 2.23 $(0.11) \%$ for control, $2.13(0.08) \%$ for wheat bran, $2.19(0.09) \%$ for oat bran, and 2.12 $(0.08) \%$ for All Bran. The proportion in the top two-fifths of the crypts was $\mathbf{2 . 6}$ $(0.6) \%$ for control, $2.15(0.5) \%$ for wheat bran, $3.3(0.9) \%$ for oat bran, and 3.1 (0.9)\% for All Bran. On analysis of whole distribution, there was no significant overall effect of diets but there was a difference between subjects. Analysis including total fibre intake also did not identify effects on proliferation.

Conclusion-In this study of high risk subjects with initial high fat diets, dietary fibre in association with a low fat diet had no effect on rectal epithelial cell proliferation, although wheat bran had the greatest effect on percentage of labelled cells in the top two-fifths of crypts.

(Gut 1997; 41: 239-244)
Keywords: cereal fibre; rectal epithelial proliferation; PCNA; fibre solubility

Diets high in fibre and low in fat seem to protect against the development of colorectal cancer. ${ }^{1-5}$ The mechanisms, however, by which fat and fibre exert their effects are not yet clear. Dietary fibre is divided into soluble and insoluble types depending on its solubility in water. ${ }^{6}$ Soluble fibres are well fermented by anaerobic bacteria in the proximal colon and seem to provide less protection against the development of colorectal cancer. ${ }^{7}$ In many studies, soluble fibres have shown an increase in tumorigenesis with only few showing any protection. ${ }^{910}$ Guar gum, oat bran and pectin are examples of soluble fibres which are fermented in the proximal colon and have little effect on tumorigenesis in distal colon. ${ }^{11}$

Epidemiological studies separating soluble from insoluble fibre identify insoluble fibre as preferentially protective. ${ }^{5}{ }^{12}$ Insoluble or poorly soluble dietary fibres, such as cellulose, lignin and wheat bran, have been shown to reduce transit time to the colon, ${ }^{13-15}$ increase the bulk of colon contents, ${ }^{811}$ and dilute and absorb carcinogens, reducing the time for interaction with intestinal epithelium. ${ }^{6}{ }^{16-18}$ These fibres survive transit to the distal colon, permitting distal fermentation to occur. ${ }^{7}$ Short chain fatty acids (SCFAs) - namely acetate, propionate and butyrate - are the main by-products of fermentation. Soluble fibres are more fermentable and produce larger amounts of SCFAs, but they are absorbed almost entirely by the colonocytes in the proximal colon. ${ }^{11}$ Fermentation of insoluble and poorly soluble fibres, however, provides a continuous supply of SCFAs along the bowel, maintaining normal colonocyte proliferation and differentiation. Butyrate is the preferred energy source for colonocytes, and has been shown to inhibit tumour cell growth of human cancer cell lines in vitro ${ }^{19} 20$ and increase differentiation markers. Poorly soluble fibres are therefore potentially capable of forcing differentiation, ${ }^{21}$ slowing proliferation ${ }^{2}$ and inhibiting tumorigenesis in the distal colon of the $\mathrm{rat}^{8}$ where human colorectal cancers are more common.

The Australian Polyp Prevention Project, ${ }^{22}$ in a randomised, controlled trial, found that unprocessed wheat bran and reduced dietary fat inhibited the development of large adenomas. In parallel with this study, we showed that this same diet reduced proliferation in the top two-fifths of crypts, although these results were not significant. Diets with wheat bran had lower levels of labelling in this marker crypt 
region of high cancer risk, than in the remaining groups $(p=0.033)$.

The aim of this study was to determine the effect of unprocessed wheat bran, unprocessed oat bran and processed wheat bran supplements on rectal epithelial proliferation when given in association with a low fat diet.

\section{Methods}

PATIENTS

Patients with at least one adenoma removed at recent colonoscopy completed a semiquantitative food frequency questionnaire to assess their fat intake. Those assessed as consuming a high fat diet were then asked to complete a four day food diary, over four consecutive days, including two weekdays and a weekend, for dietary analysis. Twenty subjects who had a fat intake of $\geqslant 36 \%$ energy as fat were recruited (11 men, nine women, 36-74 years of age, mean 56 years).

FIBRE

Unprocessed wheat bran, which contains cellulose, hemicellulose and lignin, is an insoluble fibre of low fermentability. It consists of $40 \%$ fibre, $80 \%$ of which is insoluble and $20 \%$ soluble. Unprocessed oat bran is a well fermented soluble fibre consisting of $18 \%$ fibre (50\% insoluble and 50\% soluble). Processed wheat bran (All Bran) consists of $29.6 \%$ fibre (26.6\% insoluble fibre and 3\% soluble). It is processed by cooking over a short time at a temperature of $120^{\circ} \mathrm{C}$ and a pressure of $5.9 \mathrm{MPa}$. This process is known as extrusion cooking and is commonly used to give texture to foods such as snacks, sweets, bread products, and breakfast cereals, making them more digestible. ${ }^{23}$ Chemical modifications of fibre components can occur during cooking, possibly affecting the fibre content of the wheat bran and the proportion of insoluble to soluble fibre.

STUDY DESIGN

The study was a randomised, cross-over trial with three six-week dietary periods, incorporating a different fibre supplement in each period: $25 \mathrm{~g}$ unprocessed wheat bran, $64 \mathrm{~g}$ unprocessed oat bran or $38 \mathrm{~g}$ processed wheat bran (All Bran, Kellogg Aust. Pty Ltd, Pagewood, NSW). Each of the supplements contained $11 \mathrm{~g}$ dietary fibre. Fibre supplements were pre-weighed in sachets and subjects were asked to take one a day in conjunction with a low fat diet of $\leqslant 25 \%$ energy as fat. The fat reduction was based on standard advice to patients with adenomas and to maximise the chance of detecting a difference between baseline and any of the fibre interventions. A dietician counselled each subject to achieve the target reduction in fat. At the beginning of the study, when on a monitored high fat diet (control period), and at the end of each six-week intervention period, four to six rectal biopsy specimens were taken $10-15 \mathrm{~cm}$ from the anal verge using colonoscopic biopsy forceps, without bowel preparation. Dietary intake during the study was assessed by four day food diaries completed by each subject at approximately week 4 of each period. Biopsy specimens were taken in the morning between 0900 and 1100 hours. Non-steroidal anti inflammatory drugs, aspirin and vitamin supplements, including betacarotene, were proscribed during the study.

BIOPSY SPECIMENS

Specimens were fixed in methacarn (methanol: chloroform:acetic acid, ratio $6: 3: 1$ ) for one hour, dehydrated in three changes of ethanol over three hours, cleared in three changes of chloroform over three hours, and then vacuum embedded in three changes of paraffin wax over a one hour period. Serial sections were cut at $2 \mu \mathrm{m}$ and mounted in sequence on numbered slides.

PCNA IMMUNOHISTOCHEMISTRY

Proliferating cells were stained immunohistochemically for proliferating cell nuclear antigen (PCNA) ${ }^{24}$ Briefly, sections were dewaxed and endogenous peroxidase activity was blocked in $0.9 \%$ hydrogen peroxide in methanol for 15 minutes. Sections were then fixed for five minutes in $10 \%$ neutral buffered formalin and non-specific binding sites blocked in Tris buffer containing $10 \%$ fetal calf serum for 10 minutes. The sections were incubated sequentially in a 1 in 1000 dilution of a mouse monoclonal antibody to PCNA (clone 19A2, Coulter Immunology, Hialeah, FL, USA) for 90 minutes, a 1 in 100 dilution of a rabbit anti-mouse immunoglobulin (Ig) (Dako Z259, Dakopatts, Copenhagen, Denmark), a 1 in 40 dilution of a swine anti-rabbit Ig (Dako Z196), and a 1 in 40 dilution of a rabbit peroxidase anti-peroxidase Ig (Dako Z113) for 30 minutes each. Between reagent changes, sections were washed for 10 minutes in three changes of Tris buffer. The sites of bound enzyme were visualised by incubating sections for five minutes in $100 \mathrm{ml}$ buffer containing $60 \mathrm{mg} \mathrm{3,3-}$ diaminobenzidine and $50 \mu 1 \quad 30 \%$ hydrogen peroxide. Sections were counterstained with haematoxylin and mounted in DPX.

\section{ANALYSIS OF CRYPTS}

Longitudinally sectioned crypts from surface to base, with a single layer of epithelial cells and with the lumen identifiable at least at the base were counted. Each crypt column was counted from the centre of the base of the crypt up to the level of the collagen table beneath the surface epithelium. Both columns were counted for each crypt. The total number of cells, the total number of labelled cells and the numerical position of the labelled cells per crypt column were recorded for each subject. Only cells with uniform dark brown staining of the nucleus were considered labelled.

\section{STATISTICAL ANALYSIS}

Dietary periods with respect to the labelling index and the percentage of labelled cells in the top two-fifths of the crypts were compared using analysis of variance (ANOVA). In addition, log-linear models were used with $\chi^{2}$ tests of the likelihood ratio statistic, to compare the distribution of labelled cells in the four 
TABLE 1 Comparisons of dietary intake in the four dietary groups

\begin{tabular}{|c|c|c|c|c|}
\hline \multirow[b]{2}{*}{ Daily intake } & \multicolumn{4}{|l|}{ Dietary group } \\
\hline & Control & Wheat bran & Oat bran & All Bran \\
\hline Total calories $(\mathrm{kCal})$ & $2159.2(636)$ & $1682.2(490)$ & $1643.9(533)$ & $1545.9(407)$ \\
\hline Fat (\%) & $38.5(3.2)$ & $24.7(6.3)$ & $25.6(6.0)$ & $26.5(6.4)$ \\
\hline Protein (\%) & $17.4(3.3)$ & $22.3(4.2)$ & $21.9(3.6)$ & $21.6(4.7)$ \\
\hline Carbohydrate (\%) & $38.2(8.0)$ & $47.3(9.5)$ & $47.5(7.4)$ & $47.7(8.5)$ \\
\hline Fibre (g) & $20.7(6.4)$ & $30.4(6.3)$ & $33.6(7.1)$ & $32.2(7.3)$ \\
\hline Calcium (mg) & $682.1(247)$ & $752.3(165)$ & $656.4(197)$ & $675.1(209)$ \\
\hline Betacarotene $(\mu \mathrm{g})$ & $2936 \quad(2034)$ & 2813 (1628) & $4035 \quad(2241)$ & $2714 \quad(1281)$ \\
\hline Starch $(\mathrm{g})$ & $117.0(35)$ & $103.2(39)$ & $116.0(46)$ & $102.4(43)$ \\
\hline
\end{tabular}

Results expressed as mean (SD).

crypt compartments, comprising each of the bottom three-fifths and the top two-fifths combined.

\section{Results}

Four subjects withdrew from the study after completing two interventions. All 20 subjects completed the wheat bran intervention, 19 the oat bran and 17 the All Bran intervention. Six subjects gained between 0.5 and $5.0 \mathrm{~kg}$ in weight after intervention, while eight subjects lost between 0.5 and $7.0 \mathrm{~kg}$. No data on weight were available for the remaining six subjects (mean (SD) weight before and after intervention $79.82(14.86)$ and 76.95 (12.69) $\mathrm{kg}$, respectively).

Table 1 shows the mean nutrient intakes before and after intervention. During the intervention periods, subjects reduced their fat intake to the required level of approximately $25 \%$ energy as fat, which in turn reduced their total calorie intake to an average of $1624 \mathrm{kCal}$ compared with $2159.2 \mathrm{kCal}$ for the control period. The amount of protein and carbohydrates consumed increased by $25 \%$ during the intervention periods and the amount of fibre increased by $33 \%$. The levels of calcium and starch consumed were similar for all four dietary groups; however, when subjects were on oat bran supplements, they consumed significantly greater amounts of dietary betacarotene than the other groups.

Table 2 shows the measures of proliferation. The labelling index was not affected by the reduced fat and fibre supplement interventions. The mean (SD) labelling indexes for the control, wheat bran, oat bran, and All Bran groups were $2.23(0.11) \%, 2.13(0.08) \%, 2.19$ $(0.09) \%$, and $2.12(0.08) \%$, respectively. Similarly, the comparison of the proportion of labelled cells in the top two-fifths of the crypts between groups did not reach statistical significance, although the wheat bran group had the least number of labelled cells in the top two-fifths. The mean proportions were 2.6 (0.6) \% for controls, $2.1(0.5) \%$ for wheat bran, $3.3(0.9) \%$ for oat bran, and $3.1(0.9) \%$ for All Bran. The number of cells/crypt column and the number of labelled cells/crypt column were similar for all groups (table 2).

Overall comparison of the whole distribution of labelled cells in the four crypt compartments, comprising each of the bottom three-fifths and the top two-fifths combined, showed no significant differences between groups. However, individual analysis of distribution of each subject resulted in significant differences in the distribution patterns between the four dietary groups for eight subjects $(\mathrm{p}<0.05)$ (fig 1$)$.

\section{Discussion}

Many studies have related either the proportion of demonstrable proliferating to non-proliferating cells (the labelling index), or their distribution, in rectal epithelial crypts to a subject's clinical risk of colorectal cancer. ${ }^{25-28}$ Cross sectional studies of patients with adenomas or cancers indicate that the proliferative activity at the top of colonic crypts reflects increased risk for colorectal cancer, and thereby has been used as a surrogate measure of protection against risk in intervention trials of diet and chemoprevention. Intervention trials have been published on the effects of calcium, ${ }^{29}{ }^{30}$ antioxidants, ${ }^{31}$ non-steroidal antiinflammatory drugs, ${ }^{32}$ omega-3 fatty acids, ${ }^{33}$ wheat bran, ${ }^{2}$ and other agents using colorectal epithelial cell proliferation as a surrogate end point for cancer development.

The Australian Polyp Prevention Project, ${ }^{22}$ in a randomised, controlled trial of dietary intervention, showed that a low fat diet supple-

TABLE 2 Measures of proliferation

\begin{tabular}{|c|c|c|c|c|}
\hline \multirow[b]{2}{*}{ Measure of proliferation } & \multicolumn{4}{|l|}{ Dietary groups } \\
\hline & Control & Wheat bran & Oat bran & All Bran \\
\hline No. of subjects & 20 & 20 & 19 & 17 \\
\hline No. of crypts & $24.4 \quad(4.7)$ & 25.0 & $25.2(4.0)$ & $26.3(2.8)$ \\
\hline No. of labelled cells/crypt column & $1.9(0.4)$ & $1.7(0.3)$ & $1.8(0.3)$ & $1.8 \quad(0.2)$ \\
\hline No. of cells / crypt column & $80.7 \quad(6.8)$ & $82.6(8.3)$ & $82.2(7.7)$ & $83.5 \quad(6.7)$ \\
\hline Total labelling index & $2.23(0.48)$ & $2.12(0.35)$ & $2.19(0.39)$ & $2.18(0.33)$ \\
\hline \multicolumn{5}{|c|}{ Per cent of labelled cells within compartments ${ }^{\star}$ : } \\
\hline Compartment 1 & $33.8(6.7)$ & $34.9(9.9)$ & $34.7(7.4)$ & $35.5(8.2)$ \\
\hline Compartment 2 & $44.1 \quad(6.0)$ & $44.9(7.1)$ & $42.6 \quad(4.4)$ & $43.6 \quad(6.6)$ \\
\hline Compartment 3 & $19.6(4.10)$ & $18.2(5.5)$ & $19.4 \quad(5.9)$ & $17.9 \quad(7.0)$ \\
\hline \multirow[t]{2}{*}{ Compartments 4 and 5} & $2.6(2.8)$ & $2.1 \quad(2.4)$ & \multirow[b]{2}{*}{$\frac{3.4(4.0)}{100}$} & \multirow[b]{2}{*}{$\frac{3.0(3.0)}{100}$} \\
\hline & $\frac{.00}{100}$ & $\frac{2.10}{100}$ & & \\
\hline
\end{tabular}

Results expressed as mean (SD). *Number of labelled cells in each compartment over the total number of labelled cells. 
mented with unprocessed wheat bran protects against the development of large adenomas. A parallel study demonstrated that betacarotene supplements had suppressive effects on rectal epithelial cell proliferation measured as labelling index, and the combination of low fat and unprocessed wheat bran was associated with the lowest proliferative activity in the top twofifths of rectal crypts, though this did not quite reach statistical significance. Using univariate analysis, the wheat bran intervention had lowest activity in the top two-fifths $(p=0.033)$. Wheat bran has been shown to reduce epithelial proliferation in a study of patients with

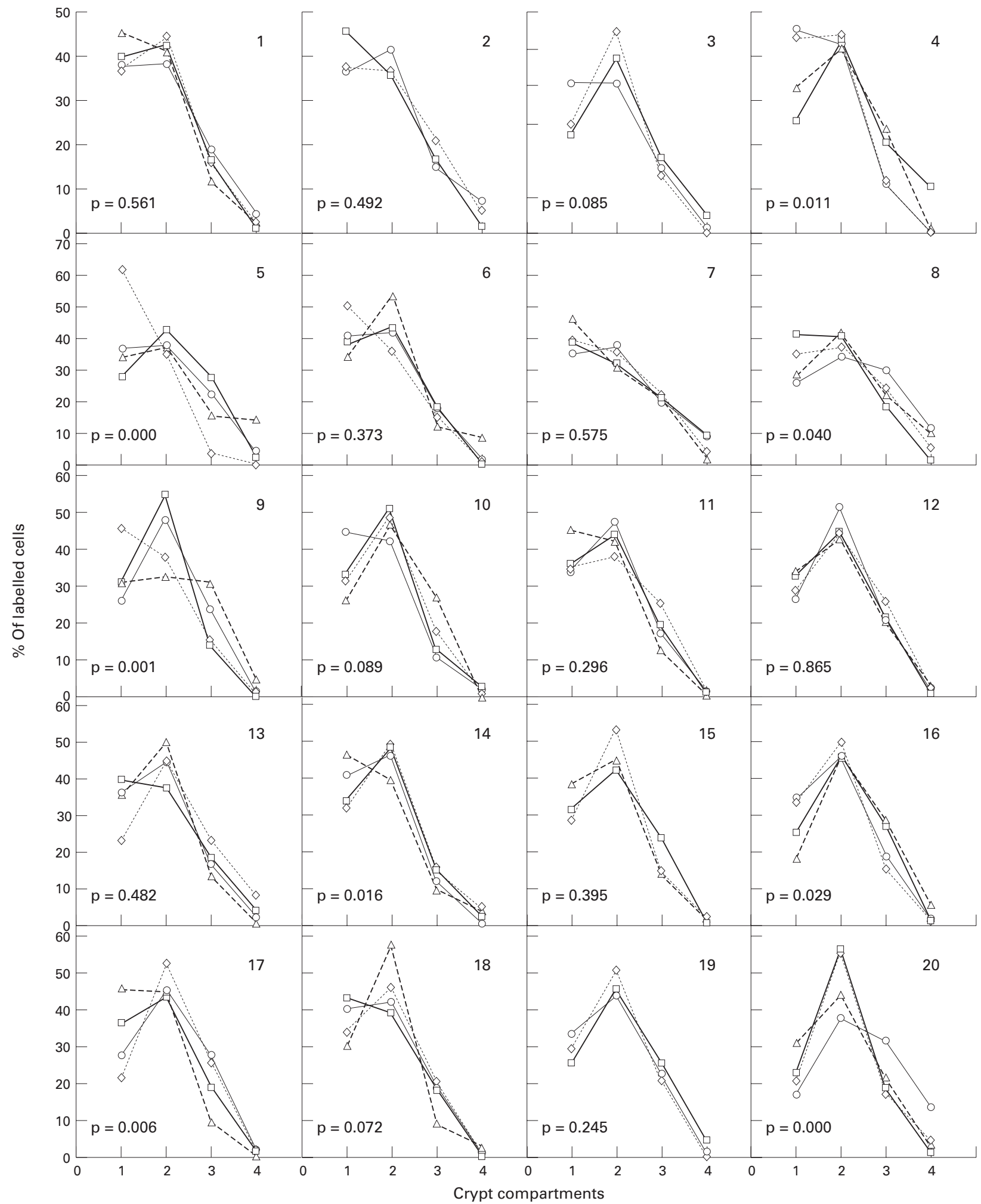

Figure 1: Individual distribution patterns for each subject and for each dietary group. Each of the graphs represents the number of labelled cells in each of the four crypt compartments, comprising the bottom three-fifth and the top two-fifths combined. Differences in the distribution patterns between the four groups were found in eight of the 20 subjects $(p<0.05)$. Control, open squares; wheat bran, diamonds; oat bran, open circles; All Bran, open triangles. 
resected colorectal cancer, but not on an intention to treat analysis. ${ }^{2}$

Unprocessed wheat bran is not especially palatable and a public health message to consume supplementary unprocessed wheat bran may not be effective due to poor compliance. We were therefore interested to see whether the effects on proliferation, which were nearly significant seen with unprocessed wheat bran, were maintained when wheat bran is processed through to the more palatable All Bran (Kellogg's). At the same time, hypothesising that the soluble fibre in oat bran would be fermented proximally and not be able to produce butyrate for rectal epithelial cell metabolism, we included oat bran as another arm in the randomised, controlled, cross-over study. ${ }^{811}$

Dietary counselling was effective in reducing fat intake to $<25 \%$ energy as fat. Mean intakes fell at least $31 \%$ from control values. Compliance to prescribed fibre intake was also good judged both by sachet reconciliation counts and dietary fibre intake. Despite this, we were unable to detect an effect of any of the supplementary fibres on labelling index. Once again, percentage of labelled cells in the top two-fifths of rectal epithelial crypts was the most sensitive measure. Possibly our sample size was too small to detect an effect (type 2 error). However, neither oat bran nor All Bran showed any suggestion of protection with any of the analytical measures used. The lack of effect of oat bran was expected on the basis of the soluble/insoluble fibre SCFA hypothesis.

It should be noted that the subjects in this study were average risk volunteers, whereas those in the Australian Polyp Prevention Project all had antecedent adenomas. It may be that the effects of wheat bran intervention are more pertinent to the high risk (possibly genetically determined) adenoma population -where dietary modulation would be most useful - than to average risk individuals with possibly already "basally" tuned cell kinetics.

Quality control of rectal epithelial cell proliferation studies is essential to validate the results. In our previous studies we have shown that labelling index has poor reproducibility characteristics but percentage of labelled cells in the top two-fifths of the crypt is less subject to interobserver variability, though it is subject to small changes in distribution of positive cells which may be of doubtful biological importance. ${ }^{24}$ Nevertheless in two studies of unprocessed wheat bran we have shown that unprocessed wheat bran together with a low fat diet has been associated with the lowest level of labelled cells in the top two-fifths of rectal epithelial crypts. ${ }^{34}$ We are thus more confident of the biological relevance of these observations. Whole distribution of labelled cells is undoubtedly the most robust analytical measure in quality control studies, but whether whole distribution analysis is sensitive enough to detect small effects of intervention agents is still uncertain in the context of our studies.

The results of this study are inconclusive; however, it has been helpful in exploring the effects of processing and solubility of cereal fibres on colorectal epithelial proliferation, in the context of the demonstrable effect observed on proliferation and tumorigenesis in the Australian Polyp Prevention Project.

This work has been supported by Kellogg (Aust.) Pty Ltd. The authors wish to thank the participants for their co-operation during the study.

Presented in part to the American Gastroenterological Association meeting, San Diego, 1995, and published in abstract form [Gastroenterology 1995; 108: A501].

1 Trock B, Lanza E, Greenwald P. Dietary fiber, vegetables, and colon cancer: Critical review and meta-analyses of the epidemiologic evidence. I Natl Cancer Inst 1990; 82: 650-60.

2 Alberts DS, Einspahr J, Rees-McGee S, Ramanujam P, Buller MK, Clark L, et al. Effects of dietary wheat bran on rectal epithelial cell proliferation in patients with resection

3 Kune S, Kune GA, Watson LF. Case-control study of deitary etiological factors: The Melbourne colorectal cancer study. Nutr Cancer 1987; 9: 21-42.

4 Willett WC, Stampfer MJ, Colditz GA, Rosner BA, Speizer FE. Relation of meat, fat, and fiber intake to the risk of colon cancer in a prospective study among women. $N$ Engl f Med 1990; 323: 1664-72.

5 Giovannucci E, Rimm EB, Stampfer MJ, Colditz GA, Ascherio A, Willett WC. Intake of fat, meat, and fiber in relation to risk of colon cancer in men. Cancer Res 1994; 54: 2390-7.

6 Alabaster O, Tang ZC, Frost A, Schivapurkar N. Potential synergism between wheat bran and psyllium: enhanced
inhibition of colon cancer. Cancer Lett 1993; 75: 53-8.

7 Kashtan H, Stern HS, Jenkins JA, Jenkins AL, Thompson $\mathrm{LU}$, Hay K, et al. Colonic fermentation and markers of colorectal-cancer risk. Am f Clin Nutr 1992; 55: 723-8.

8 McIntyre A, Gibson PR, Young GP. Butyrate production from dietary fibre and protection against large bowel cancer in a rat model. Gut 1993; 34: 386-91.

9 Cameron IL, Ord VA, Hunter KE, Heitman DW. Colon carcinogenesis: modulation of progression. In: Moyer MP, carcinogenesis: modulation of progression. In: Moyer MP, Poste GH, eds.
Press, 1990: 63-84.

10 Jacobs LR. Modification of experimental colon carcinogenesis by dietary fibres. Adv Exp Med Biol 1986; 206: 105-18.

11 McIntyre A, Young GP, Taranto T, Gibson PR, Ward PB. Different fibers have different regional effects on luminal contents of rat colon. Gastroenterology 1991; 101: 1274-81.

12 Freudenheim JL, Graham S, Horvath PJ, Marshall JR, Haughey BP, Wilkinson G. Risks associated with source of fiber and fiber components in cancer of the colon and rectum. Cancer Res 1990; 50: 3295-300.

13 Jacobs LR, Lupton JR. Relationship between colonic luminal $\mathrm{pH}$, cell proliferation, and colon carcinogenesis in 1,2-dimethylhydrazine treated rats fed high fiber diets. Cancer Res 1986; 46: 1727-34.

14 Burkitt DP. Epidemiology of cancer of the colon and rectum. Cancer 1971; 28: 3-13.

15 Cummings JH. Constipation, dietary fibre and the control of large bowel function. Postgrad Med $\mathcal{F} 1984 ; 60$ : 811-9.

16 Cameron IL, Ord VA, Hunter KE, Padilla GM, Heitman DW. Suppression of a carcinogen (1,2-dimethylhydrazine dihydrochloride)-induced increase in mitotic activity in the colonic crypts of rats by addition of dietary cellulose. Cancer Res 1989; 49: 991-5.

17 Edwards CA, Wilson RG, Hanlon L, Eastwood MA. Effect of the dietary fibre content of lifelong diet on colonic cellular proliferation in the rat. Gut 1992; 33: 1076-9.

18 Slattery ML, Sorenson AW, Mahoney AW, French TK, Kritchevsky D, Street JC. Diet and colon cancer: Assessment of risk by fiber type and food source. $\mathcal{F}$ Natl Cancer Inst 1988; 80: 1474-80.

19 Kruh J, Defer N, Tichonicky L. Effect of butyrate on cell proliferation and gene expression. In: Cummings $\mathrm{JH}$, Rombeau JL, Sakata T, eds. Physiological and clinical aspects of short chain fatty acids. Cambridge: Cambridge University Press, 1994: 275-88.

20 Young GP, Gibson PR. Butyrate and the human cancer cell. In: Cummings JH, Rombeau JL, Sakata T, eds. Physiological and clinical aspects of short chain fatty acids. Cambridge: Cambridge University Press, 1994: 319-35.

21 Gibson PR, Folino M, Rosella O, Finch CF, Moeller I, Alexeyeff $\mathrm{M}$, et al. Neoplasia and hyperplasia of large terology 1992; 103: 1452-9.

22 MacLennan R, Macrae FA, Bain C, Battistutta D, Chapius $\mathrm{P}$, Grattan $\mathrm{H}$, et al. Randomized trial of intake of fat, fibre and betacarotene to prevent colorectal adenomas. $\mathcal{F}$ Natl Cancer Inst 1995; 87: 1760-6.

23 Sandberg AS, Anderson H, Carlsson NG, Sandstorm B. Degradation products of bran phytate formed during digestion in the human small intestine: Effect of extrusion cooking on digestibility. 7 Nutr 1987; 117: 2061-5.

24 Macrae FA, Kilias D, Sharpe K, Hughes NR, Young GP, MacLennan R. Rectal epithelial cell proliferation: Comparison of errors in measurement with intersubject variance. $\mathcal{F}$ Cell Biochem 1994; 269 (suppl 19): 84-90. 
25 Terpstra OT, Blankenstein M, Dees J, Eilers GAM. Abnormal pattern of cell proliferation in the entire colonic mucosa of patients with colon adenoma or cancer. Gastroenterology 1987; 92: 704-8.

26 Lipkin M, Enker WE, Winawer SJ. Tritiated thymidine labelling of rectal epithelial cells in non-prep biopsies of individuals at increased risk for colonic neoplasia. Cancer Lett 1987; 37: 153-61.

27 Ponz de Leon M, Roncucci L, Di Donato P, Tassi L, Smerieri O, Amorico MG, et al. Pattern of epithelial cell proliferation in colorectal mucosa of normal subjects and of proliferation in colorectal mucosa of normal subjects and of patients with adenomatous polyps
bowel. Cancer Res 1988; 48: 4121-6.

28 Anti M, Marra G, Armelao F, Bartoli GM, Ficarelli R, Percesepe A, et al. Effect of $\omega-3$ fatty acids on mucosal cel proliferation in subjects at risk for colon cancer. Gastroenterology 1992; 103: 883-91.

29 Wargovich MJ, Isbell G, Shabot M, Winn R, Lanza F, Hochman L, et al. Calcium supplementataion decreases rectal epithelial proliferation in subjects with sporadic adenoma. Gastroenterology 1992; 103: 92-7.
30 Rozen P, Fireman Z, Fine N, Wax Y, Ron E. Oral calcium suppresses increased rectal epithelial proliferation of persons at risk of colorectal cancer. Gut 1989; 30: 650-5.

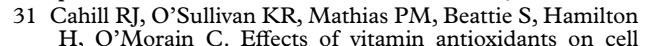
$\mathrm{H}$, O'Morain C. Effects of vitamin antioxidants on cell kinetics of patients with adenomatous polyps. Gut 1993; 34: 963-7.

32 Nugent KP, Farmer KC, Spigelman AD, Williams CB, Phillips RK. Randomised controlled trial of the effect of sulindac on duodenal and rectal polyposis and cell proliferation in patients with familial adenomatous polypoproliferation in patients with fam
sis. Br f Surg 1993; 80: 1618-9.

33 Anti M, Marra G, Armelae F, Percesepe A, Ficarelli R, Ricciuto GM, et al. Rectal epithelial cell proliferation patterns as predictors of adenomatous colorectal polyp recurrance. Gut 1993; 34: 525-30.

34 Macrae FA, Kilias D, Hughes, Selbie L, Brouwer R, Sharpe $\mathrm{K}$, et al. Effect of dietary intervention on distribution of labelled cells in rectal epithelial crypts: A 4 year randomised controlled trial [abstract]. Gastroenterology 1995; 108: A501. 